\title{
Effective Marketing Strategies for a Medical Laboratory Science Program
}

\begin{abstract}
The medical field is in dire need of more qualified medical laboratory scientists (MLS) and medical laboratory technicians (MLT). Medical laboratory educational programs are diminishing, and medical staff in hospitals are unaware of the unequivocal value trained lab scientists bring to the quality of their patients' lab results. The national need for more qualified laboratory testing personnel is outpacing the supply. A survey to determine current marketing trends and methods was sent out to 469 program directors of MLS and/or MLT programs, with a $35 \%$ response rate. Responses were compared with proven marketing methods to give marketing suggestions relevant to the MLS field.

This paper describes the research in how MLS programs currently market themselves. Explanations of marketing techniques are discussed with the intent to help simplify marketing efforts for a more effective marketing strategy. This study showed that medical and clinical laboratory educational programs nationwide should increase marketing and promote the MLS value to local communities.
\end{abstract}

\author{
ABBREVIATIONS \\ NAACLS - National Accrediting Agency for Clinical Laboratory Science, MLS - Medical \\ Laboratory Scientist, MLT - Medical Laboratory Technician. ASCP - American Society for \\ Clinical Pathology, ASCLS - American Society for Clinical Laboratory Science
}




\section{INDEX TERMS}

Medical Laboratory Science, Marketing, Medical Laboratory Technician, Education, NAACLS

\section{INTRODUCTION}

The medical laboratory science profession is not producing enough graduates to keep pace with market demand. The American Society for Clinical Pathology recently published an article stating, “...the enrollment and graduation of medical laboratory professionals is not keeping up with the rapidly rising demand, as the profession is educating less than half of the number of laboratory professionals needed."1

The Bureau of Labor Statistics has estimated the field of medical laboratory science will see an increased need of $11 \%$ in the profession from 2018-2028. ${ }^{2}$ An increase of this magnitude would result in 3,648 additional MLS/MLT needed per year. When combined with attrition numbers, there is demand for roughly 12,000 new medical laboratory professionals per year. ${ }^{3}$ By current ASCLS estimates, MLS educational programs are graduating around 5,000 new technologists per year. ${ }^{3}$ Since 1990 the number of schools that train medical lab scientists has decreased by nearly $15 \% .^{4,5,6}$ This shortage has been well documented, but little has been done to alleviate it.

The reasons for the shortage have been explained by lack of clinical rotation seats, increased testing demands for the aging population, increases in retirement, non-competitive pay, and demanding work schedules. However, the biggest factor may still be that the value of MLS as a profession is largely unknown and not marketed well. Physical locations of hospital laboratories are often secluded. The only physical interactions with patients and hospital staff 
are with phlebotomists who are not qualified to share testing recommendations or interpretation of results. Hence, it should come as no surprise that most people are unaware that this profession extends beyond specimen collection. ${ }^{7}$

Marketing can be simplified down to the four P's: product, price, place, and promotion. ${ }^{8}$ Marketing efforts of programs were evaluated through these marketing principles and targeted marketing methods are suggested.

\section{METHODS AND MATERIALS}

A thorough literature search was performed using Google Scholar to find the marketing methods used in the educational industry to enhance laboratory science education. The search was limited to articles within the last ten years regarding MLS and MLT educational programs. A marketing assessment survey discussing current market trends and marketing methods (see Figure 1) was sent to 469 program directors of NAACLS accredited programs. The survey was anonymous to encourage participation. The marketing assessment survey was built using Qualtrics, an online survey tool, and was sent via emails obtained on the NAACLS website.

The survey received 163 responses, equating to 35\% participation. The research performed was exempt by the IRB committee.

Data was analyzed using the Qualtrics program to understand three categories: the perceived demand of MLT and MLS positions in hospitals, program student capacity, and current marketing methods. The results of the survey were compared to proven marketing methods and how they are utilized by medical laboratory educational programs. 


\section{RESULTS}

Survey results with regard to program demographics showed that nearly one-half $(47 \%)$ are MLS programs only, and the other half (48\%) are only MLT. Five percent (5\%) responded to awarding both MLT and MLS degrees. The majority of responding programs (79\%) are university-based and the remaining $(21 \%)$ are hospital-based programs. The vast majority (77\%) responded to graduating between 5-20 students per year, while few (19\%) graduate > 20 students per year.

Figure 2 shows the percentage of responses from program directors when asked to what level their program engages in marketing. Nearly $29 \%$ said they actively market their programs and $51 \%$ replied to occasionally marketing their program. The remaining $19 \%$ have simply discussed marketing or have not done anything to market their programs. When asked if their program had a marketing plan, almost half (49\%) indicated they did, while more than half $(51 \%)$ of programs did not.

When asked if there is a shortage of laboratory personnel in their respective regions and the perceived effect of marketing methods could have on matriculation numbers, most (98\%) said they see a shortage of qualified medical laboratory personnel in their region, and most (91\%) believe that a structured marketing plan could help them increase matriculation numbers (figures 3.A and 3.B.) For those that indicated that they market their program, the results were mixed. A little under half of respondents (48\%) felt that their marketing had increased matriculation numbers, while more than half (52\%) felt that their marketing efforts did not make any difference

Thirty-six percent (36\%) felt marketing was a priority for them this year (Figure 3.C). Most 
(63\%) percent said that they were either unsure or are not making marketing a priority this year.

Hesitancy and uncertainty proved to be a reason that programs do not execute marketing and many (68\%) said that they need more support or guidance when it comes to developing a marketing plan and executing it.

Figures 4 and 5 show the various marketing efforts used by programs. A majority (79\%) of programs have a website. Over half (51\%) of programs indicated they use social media. Of those that have social media accounts, $69 \%$ engage or update these accounts more than once a month. Facebook was the most popular platform utilized at 96\%. Second to Facebook was Instagram at $20 \%$ utilization.

\section{DISCUSSION}

The goal of this paper is to provide marketing tools for laboratory science programs and enhance awareness of strategies for building effective marketing plans, to increase market presence, enhance public awareness of the profession, and ultimately increase student matriculation numbers to fill the void in the workforce.

Defining the target market, or potential customers helps fine-tune the entire marketing process and channels resources into effective areas. ${ }^{8}$ For example, target market individuals could be in high schools, on social media platforms, in hospitals, in laboratories, and on college campuses. In fact, marketing on-campus can be very effective. A recent study showed that more than 50 percent of students who have enrolled in college are undecided about their major, and an estimated 75 percent of students will change their major. ${ }^{9}$ 
With targeted marketing in mind, survey responses were compared against the four P's of marketing, with product and promotion being the primary focus.

Product. The product is the education and certifications the student receives. Each attribute of the product mentioned below can be used in promotion materials and other mediums. For example, successful certification pass rates, graduation rates, and flexibility of the program can all be used as marketable points in mailed media, social media, and on-campus marketing. There are several factors to consider about the product:

- Graduation rates. Posting graduation rates increases students' understanding of the path (and the difficulty thereof) to successfully graduating. Factors decreasing graduation rates include heavy course loads, unnecessary class requirements, and excessive prerequisites and generals, which can deter students from pursuing the MLS profession.

- Accreditation. The quality of the product is directly tied to proper accreditation. Posting updated accreditation may help increase student interest and matriculation.

- Board of Certification Pass Rates. If the program's first-time pass rates are consistently below the national average, then these programs may have a product problem. Identifying the areas that are lacking in the product and increasing time and resources into improving them can improve the interest in your program.

- $\quad$ Flexibility. Rigid schedules such as established laboratory and lecture times are barriers for many students. ${ }^{10}$ There are flexible options for students to earn a great education. Programs must evolve to meet the challenging needs of individuals who want to pursue a career in medical laboratory science. Although there is not a perfect solution for every program, this may be an opportunity to think outside the box. Examples may include 
intermittent online or virtual laboratories, flipped classrooms, online lectures, shortened clinical rotations, blocked classes, open labs, etc.

- Branding. Creating a program brand, story, mission, or logo helps with immediate association, and often creates a positive emotional response to a product. ${ }^{11,12}$

Price. Understandably, tuition costs can be non-negotiable for university and hospital-based programs. However, individuals seeking degrees are no longer restrained to their state borders, nor do they need to move to benefit from lower tuition rates at other universities. Programs should compare their tuition rates against other programs and promote scholarship opportunities to entice student applications.

Place. Education does not have to be from a brick and mortar school. Distance educational models can deliver didactic material to students in rural areas where MLS shortages are apparent and recruiting qualified employees is difficult. Therefore, distance-learning models may help increase student matriculation and ease the shortage in the profession.

Promotion. Promoting the product is crucial for MLS growth. However, $71 \%$ indicated that they are not actively marketing their programs even though almost all (98\%) of the program directors responded to seeing a shortage of laboratory personnel in their areas. Only $33 \%$ of programs stated marketing was a priority for them this year (See figure 3.C).

The survey also asked respondents to place in order their greatest barriers to marketing. The majority (80\%) responded not enough time as their primary or secondary reason. The next most common answer was marketing is too expensive. These two responses indicate that promotion in this field needs to be a simplified, inexpensive, and strategic endeavor. For many 
university- based and hospital-based programs, advertising services are available. Seeking out graphic designers, marketing departments, and web support teams on campus can help aid in the development of a targeted marketing plan. Occasionally, business or marketing departments on campus look for capstone projects for advanced students, translating into a mutually beneficial marketing project.

Here are a few proven and relatively inexpensive marketing methods to immediately increase student awareness. Ensure each marketing step can be measured based on effectiveness.

- Engage in the community. A large portion of the target market exists in the immediate community so engaging in the community can be one of the most productive marketing efforts. Many programs are exploring this option. Word of mouth and high school recruiting were the two most preferred marketing methods. (See figure 4) Attending university and college events, science events, conferences, high schools, and/or creating events regarding lab science, increase awareness of the laboratory sciences as a profession and poses it as an option for potential students. ASCLS urges MLS programs to become engaged and associated with STEM to enhance awareness and increase scholarship opportunities. ${ }^{1}$ Organizing a travel kit with microscopes, blood smears, and parasites often amaze prospective students and arouse interests.

Many student leaders and club members require leadership and volunteer hours. Students may be given the responsibility for organizing events and presenting at various venues. In appropriate courses, instructors can create class assignments or provide extra credit for students who are involved in community engagement surrounding the MLS profession. This not only acts as a recruiting campaign on behalf of the program, but also fosters an MLS marketing culture within 
current students and alumni. Using students in this capacity saves time for faculty and staff, alleviating one of the largest barriers to marketing. Measuring methods can include asking applying students how they discovered the program (i.e. www.mlsuniversity.edu/mls/community) to calculate the effectiveness of this method.

- Advising. The gatekeepers and influencers on campus are academic advisors. Advisors and students may not be aware of MLS as a career. Sell the profession to advisors so they can accurately promote it to the students. Take time to leave promotional items (i.e. brochures), pamphlets, flyers, graduation paths, employment rates) with advisors and clearly explain the numerous opportunities the laboratory profession has to offer. Make it easier for them to distinguish your program over another to give your department a competitive advantage. These approaches may enhance the prospect of increased student applications.

Effectiveness of this approach can be determined with a unique, trackable website on the brochures that are directly tied with advising to measure online traffic (i.e. www.mlsuniversity.edu/mls/advising). The application form may include a question that asks if the student found out about the profession through his/her advisor.

- $\quad$ Targeted mail media. Sending recruitment materials out through the mail seems like an antiquated concept, but it is still a great way to get information out to targeted populations. Contact laboratories in the region with promotional swag. Magnets, stress balls, mouse pads, stickers, and pens always find a home in the clinical lab. These items may also include a unique website to measure the effectiveness of mailed media (i.e. www.mlsuniversity.edu/mls/contact).

- Website. Almost every promotional move is done to direct the student to the website. Every program needs to have a website, yet $20 \%$ of programs indicated they do not have 
one. This is the current model for effective online marketing. Search engine optimization (SEO) can be a valuable process to make sure that the program is among the top in keyword searches. Keywords are used to attract online traffic in search engines. Keyword tools, such as Keywords Everywhere, can be downloaded to reveal top key phrases, level of competition of keywords, and their cost per click (CPC) for optimal SEO results. SEO can be a powerful tool to increase the likelihood of visibility on the first page of a search engine. However, be mindful that paying per click can be expensive. (See figure 6). A call to action should be included on the website for potential students in the form of "Learn More" or "Apply Now". Upon website visitation, emails should also be collected for future promotions.

- Social Media. Program directors indicated only 40 percent of programs have a social media page, and less than half update it once a month. (See figure 5) Facebook, Instagram, Snapchat, and Twitter are all platforms to engage the laboratory profession. Social media is a simple and inexpensive way to market to prospective students and can give incredible data to clicks, views, likes, and shared pages. Some social media platforms also give advice on which target market may have an increased likelihood of success. Creative topics and discussions surrounding lab science can target high school students, undecided freshmen, pre-professional students, and lab employees looking for advancement. However, social media can be time consuming to manage, especially if there is a lack of strategy. Measurement of campaign success is built into the platform, and data can be generated to inform the department whether their marketing goals are being met. ${ }^{13}$

- Traditional advertising. This is the first method that comes to mind for many people when marketing is mentioned. Static advertising such as billboards, magazine ads, bus benches 
and other forms can be an effective way to advertise to local populations. This type of advertising increases brand awareness. However, static advertising can be expensive and the return on investment can be difficult to measure. If a program uses traditional advertising, keep the target market in mind. Try to incorporate trackable data and understand that this marketing is more for exposure than driving traffic. Targeted static media could include ads in campus newspapers, posters, and professional journals. These forms of media may produce lower yield for dollars spent.

\section{CONCLUSION}

The results of the survey sent to program directors revealed marketing is not being done to the scale needed. Many hold to the belief marketing yields little benefits. Others indicated they do not have time to market. Marketing can be time consuming. However, an effective, properly executed, targeted marketing campaign increases awareness and eventually brings more students to a lab science program. This will aid in the continual production of qualified laboratory personnel, filling the gap in the workforce.

There is not one answer to effective marketing. Many programs have limitations in staff, money, and time other programs may not have. The important message is to start. Some methods will work, and some will not. Focus on the Product and Promotion of the four P's. There are prospective students who are unaware of the laboratory profession. It is the responsibility of the educational programs to expand their marketing efforts to reach these students. Shortages cannot be addressed until awareness of the MLS profession is enhanced. Weber State's MLS Department plans to release the marketing methods that have been successful and those that were not for their program. 


\section{ACKNOWLEDGEMENTS}

We appreciate the talents of Amy Hajdas, graphic designer.

\section{REFERENCES}

1. Addressing the Clinical Laboratory Workforce Shortage. (2018, August 2). Retrieved from The American Society for Clinical Laboratory Science: https://www.ascls.org/position-papers/321-laboratory-workforce/440-addressing-theclinical-laboratory-workforce-shortage

2. Medical and Clinical Laboratory Technologists and Technicians. (2018, June 1). Retrieved from Bureau of Labor Statistics:

https://www.bls.gov/ooh/healthcare/medical-and-clinical-laboratory-technologists-andtechnicians.htm\#tab 1

3. CLINICAL LABORATORY PERSONNEL SHORTAGE. (2017). Retrieved from The American Society for Clinical Laboratory Science: https://www.ascls.org/advocacyissues/workforce

4. Scott, K. (2015). The Laboratory Workforce Shortage Demands New Solutions. American Association for Clinical Chemistry.

5. Shane Lawson, C. L. (2018). The Importance of Traditional Education in Medical Laboratory Science. American Journal of Clinical Pathology, S132.

6. Staff, A. (2016, December 5). Laboratory Personnel Shortages. Retrieved from Elite Learning: https://www.elitecme.com/resource-center/laboratory/laboratory-personnelshortages/ 
7. Doby, C. F. (2016). Awareness of Clinical Laboratory Sciences and the shortage of Clinical Laboratory Scientists in the 21st Century. Walden University Scholar Works.

8. Burrow, J. L., \& Fowler, A. R. (2015). Marketing 4th edition. Boston: Cengage Learning.

9. Freedman, L. (2013). The Developmental Disconnect in Choosing a Major: Why Institutions Should Prohibit Choice Until Second Year. The Mentor.

10. Nontraditional Undergraduates Definitions and Data. (1996). Retrieved from National Center for Education Statistics: https://nces.ed.gov/pubs/web/97578e.asp

11. Sinha, A. (2018, May 24). Six Reasons Branding is More Important Than Ever. Retrieved November 1, 2019, from Entrepreneur.com: https://www.entrepreneur.com/article/313369

12. Maha Mourad, C. E. (2011). Brand Equity in Higher Education. Marketing Intelligence and Planning, 403-420.

13. Rand, P. M. (2014). Highly Recommended: Harnessing the Power of Word of Mouth and Social Media to Build Your Brand and Your Business. Mcgraw Hill. 


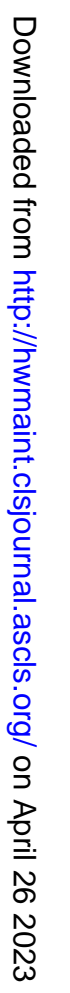


1. Have you seen a shortage of qualified medical laboratory personnel in your region?

2. Do you believe that a structured marketing plan could help to bring students into your medical laboratory program?

3. What type of certification(s) do you offer?

4. Which is the best fit of the program you are running?

5. How many graduates do you have per year?

6. What size of an increase in students could your program sustain over a 1 year period?

7. What do you feel is the main reason your program is at capacity?

8. To what level does your program engage in marketing efforts?

9. Does your program have a marketing plan?

10. Have you seen an increase in matriculation numbers that correspond with your marketing efforts?

11. What are some of the barriers that prevent your program from expanding your marketing efforts? (place them in order of importance with 1 being most important and 5 being least)

12. What marketing mediums has your program attempted? (choose all that apply)

13. What social media accounts have you set up for your medical lab education program?

14. How often do you update or add new content to your program's social media accounts?

15. Do you have a website that is specific to your laboratory education program?

16. Do you use the website as a marketing/recruiting tool?

17. Is increasing your program's marketing efforts a priority for you this year?

18. Do you feel that you need more support or guidance in developing a marketing plan and executing it?

19. Did this survey encourage you to look into more marketing mediums?

20. Please feel free to add any comments or opinions that you have about marketing MLS/MLT educational programs. Please explain what you feel works, or what you feel does not work.

Figure 1: Survey questions sent to NAACLS accredited MLS and MLT program directors. 


\section{FIGURE 2}

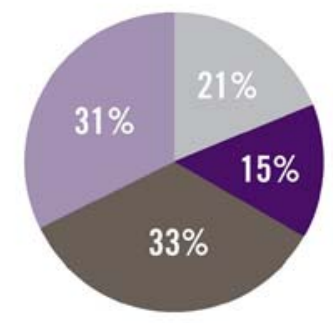

Does your program have a marketing plan?

Definitely yes Probably yes Drobably not Definitely not

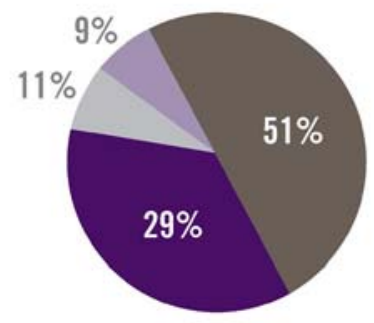

Engagement in marketing efforts?

actively market accasionally market Discussed marketing Do not market

Figure 2: Percentage of responses from program directors when asked about marketing their program. 


\section{FIGURE 3}

A.

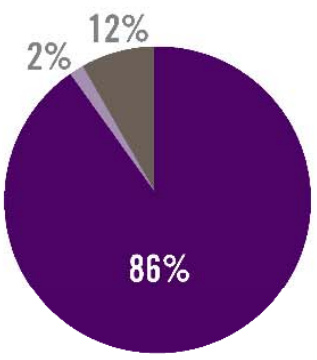

Have you seen a shortage of laboratory personnel in your region?

Definitely yes Probably yes - Probably not Definitely not
B.

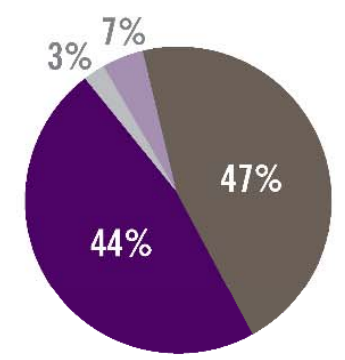

Could structured marketing bring in more students?

Definitely yes Probably yes Probably not Definitely not
C.

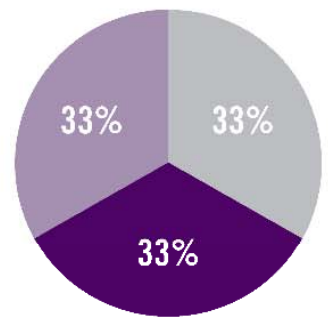

Is marketing a priority for your program this year?

- Yes Maybe No

Figure 3: Percentage of MLS program directors that have seen a shortage of laboratory personnel, if they believe marketing could help and whether marketing will be a priority in the coming year. 


\section{FIGURE $4 \quad$ Marketing efforts used by programs}

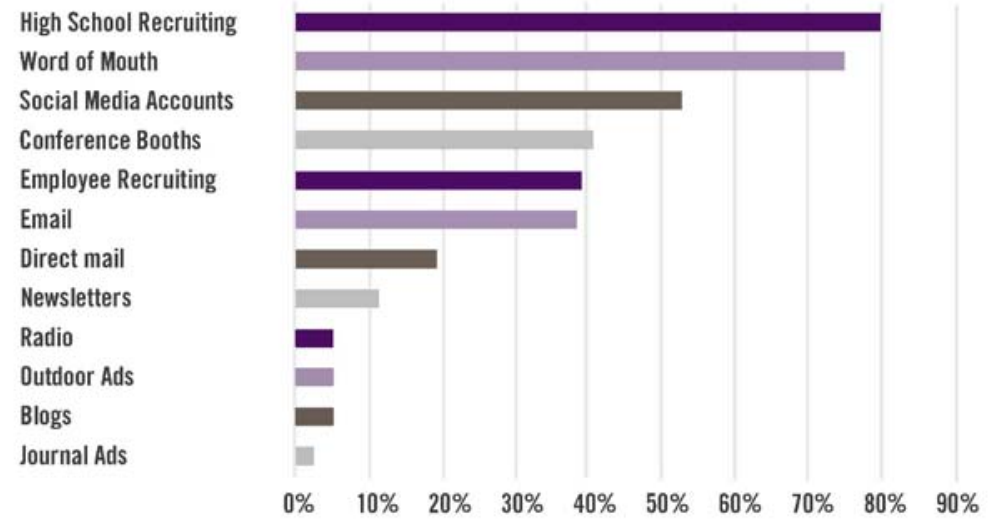

Figure 4: Percentage of programs using select marketing methods. 


\section{FIGURE 5}

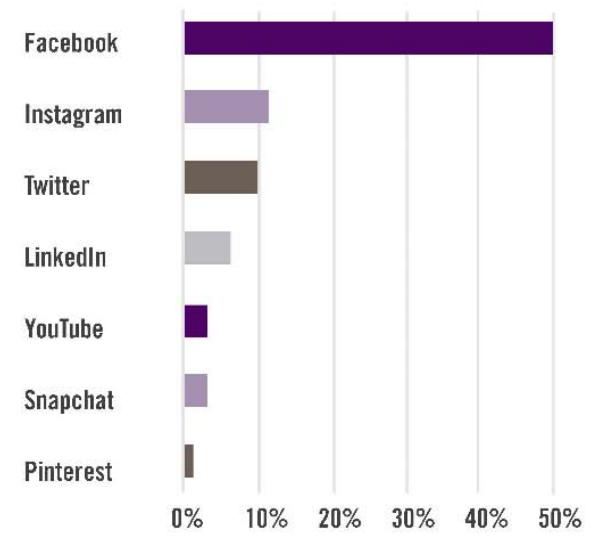

Percentage of social media platforms used

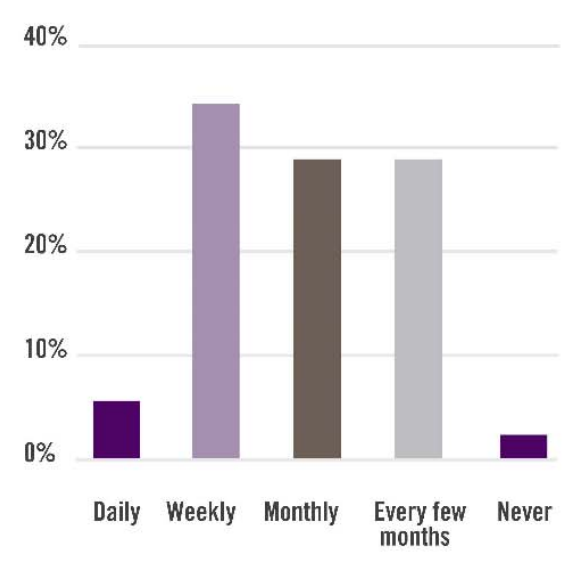

How often is the social media account updated?

Figure 5: Percentage of MLS/MLT programs that have social media accounts. Excluded from this graph are Snapchat and Pinterest that accounted for less than 2\% of responses. 


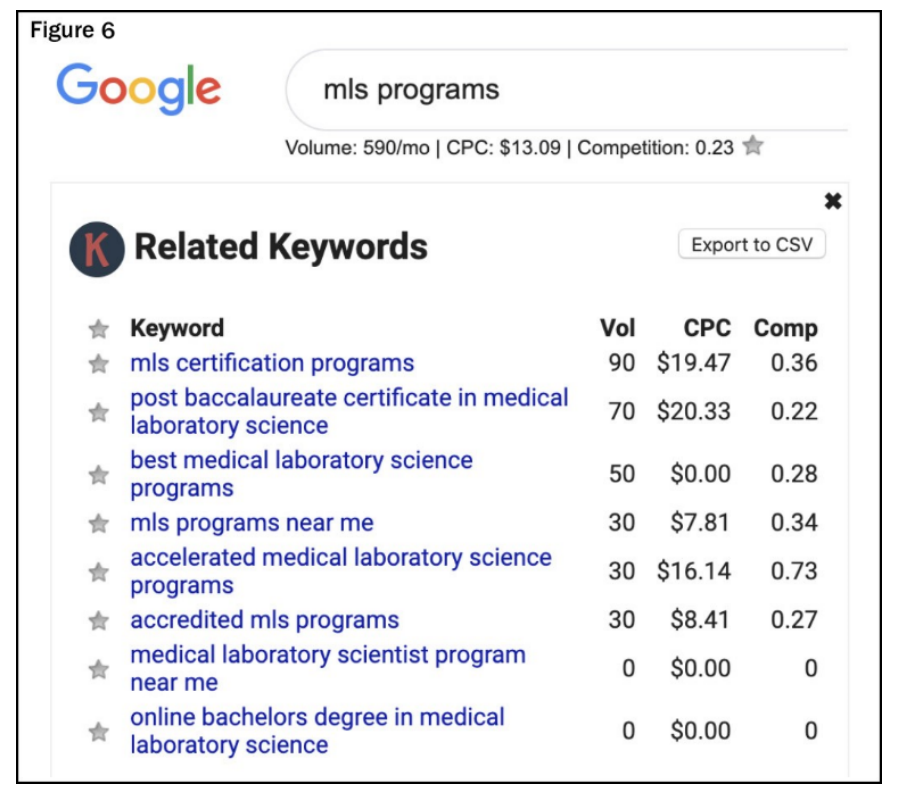

Figure 6: an example of an individual typing in "mls programs" into the Google search engine, using the extension Keywords Everywhere. 